\title{
NOVEL DIFFUSION-DILUTION METHOD FOR RELEASE OF SEMIOCHEMICALS: Testing Pheromone Component Ratios on Western Pine Beetle
}

\author{
JOHN A. BYERS \\ Department of Animal Ecology, University of Lund \\ S-223 62 Lund, Sweden \\ Department of Entomological Sciences, University of California \\ Berkeley, California 94720
}

(Received September 22, 1986; accepted January 20, 1987)

\begin{abstract}
Each of the pheromone components of the Western pine beetle, Dendroctonus brevicomis LeC. (Coleoptera: Scolytidae), exo-brevicomin (E) and frontalin $(\mathrm{F})$, were released in the forest at various ratios $0.01: 1,0.1: 1$, or $1: 1$ to a constant dose of the opposite component ( $\mathrm{E}$ or $\mathrm{F}$ ) plus the host monoterpene myrcene $(\mathrm{M})$, which were each released at $1.5 \mathrm{mg} /$ day. The components were released by a new method that combines the principles of chemical diffusion through a tube with mole percentage dilution of the chemical. Both sexes of $D$. brevicomis were attracted similarly at comparable ratios (and release rates) of $\mathrm{E}$ or $\mathrm{F}$ and showed similar logarithmic relationships $\left(r^{2}=0.92-0.99\right)$. The bark beetle predator, Temnochila chlorodia (Mannerheim) (Coleoptera: Trogositidae) was apparently less sensitive to $E$ than $D$. brevicomis, being relatively less attracted to amounts of $\mathrm{E}$ equivalent to that released by 70 females, while none were attracted to that from seven females (while this rate still attracted significant numbers of conspecifics). The apparent insensitivity of bark beetles to extreme ratios between pheromone components in contrast to moths is discussed. The advantages of the diffusion-dilution method of releasing semiochemicals compared to previous methods of absorbents, wicks, capillary tubes, and semipermeable plastic membranes are also discussed.
\end{abstract}

Key Words-Dendroctonus brevicomis, Coleoptera, Scolytidae, Temnochila chlorodia, Trogositidae, pheromone, frontalin, exo-brevicomin, myrcene, controlled release. 
Knowledge of qualitative and quantitative release of synthetic semiochemicals from dispensers is of major importance to the understanding of the chemical ecology of an organism. During isolation of relevant semiochemicals, one must usually dispense volatile compounds in order to evoke certain behaviors which can then be compared to the natural ecology. Thus, scientists are interested in simulating and experimenting with these natural processes by varying the release rates of semiochemicals and quantifying the behavioral reactions. Generally, with a laboratory or field bioassay, the experimenter wants to know (1) the purity of the semiochemical and whether it remains pure during the test and (2) the semiochemical's rate of release and whether it remains constant. One usually wants to release a very pure semiochemical whose purity remains constant and to know that the exact release rate remains constant during the test. Ideally, one should be able to adjust the release rates to any specified amount conveniently and within a range of several orders of magnitude. To date I know of no release methods which allow experimenters this degree of power-but such a method is presented here.

Several methods have been used in varying degrees with advantages and disadvantages for the experimenter. Some of these methods include: (1) release from wicks in bottles containing pure semiochemicals or solvent mixtures, (2) release from rubber septa that have absorbed semiochemical, (3) release from semipermeable plastic bags or vials containing semiochemical, and (4) release from open-ended tubes of glass or other inert material containing semiochemical. These methods, discussed in more detail later, all have one or more disadvantages, such as uneven release rates over time, possible reactive effects on the semiochemicals, or they are inconvenient to specify or vary the release rate (which is often practically limited to a narrow range). In this paper, a new method for releasing semiochemicals, which combines the principles of volatile gas diffusion through a tube (Fick's first law) with Raoult's law of vapor pressures for mixtures of volatile liquids, is presented.

In bark beetles (as in most other previous insect studies), the release of synthetic pheromone components has usually been done at only one level. The level was not necessarily similar to the natural release rate, and often the experimenter had only a rough estimate of the degree of correspondence (Roelofs, 1979). In fact, a compound cannot be properly termed a semiochemical until the synthetic release and behavioral response is determined at levels that correspond to the natural biologic condition. This is a major problem in chemical ecology and, until quite recently, has generally been ignored because of practical difficulties. Natural release rates of pheromone from bark beetles, which must feed in order to produce it, have been especially difficult to measure because of the low amounts relative to host volatiles (Schlyter et al., 1987a). 
Browne et al. (1979) and Schlyter et al. (1987a) are among the few who have determined the average release rate of pheromone from bark beetles feeding in a host tree. The former estimated that a female Western pine beetle (Dendroctonus brevicomis LeC. (released her pheromone component, $(+)$-exo-brevicomin $(\mathrm{E})$, at $4.1 \mu \mathrm{g} /$ day, while the male released his component, (-)-frontalin (F), at $0.86 \mu \mathrm{g} / \mathrm{day}$. Together these two components with the host monoterpene myrcene $(\mathrm{M})$, released by boring activity at $410 \mu \mathrm{g} /$ day/entrance hole (Browne et al., 1979), are equally attractive to both sexes (Wood et al., 1976). Tilden and Bedard (1985) have used these component ratios to test three release rates over two orders of magnitude $(1 \times, 10 \times$, and $100 \times)$ compared to similar levels of a $1: 1: 1(\mathrm{E}: \mathrm{F}: \mathrm{M})$ ratio. Their release rates of the active enantiomers of the 1:1:1 mixture at the $1 \times$ level began at amounts equivalent to that released by 52 females and 220 males according to calculations based on the results of Browne et al. (1979), assuming beetles release pure enantiomers (Stewart et al., 1977). The highest level $(100 \times)$ was equivalent to 5200 females and 25,000 males. Tilden and Bedard (1985) also tested a 5:1:400 (E:F:M) ratio at $1 \times$, $10 \times$, and $100 \times$ (i.e., 87 females and 76 males at $1 \times$ ), but since the ratios of more than one component were varied simultaneously and the levels of all components were different from the $1: 1: 1$ ratio and level, they could not easily determine the effects of various component ratios. Very few studies, in fact, have investigated the behavioral effects of pheromone component ratios in Scolytidae (Schlyter et al., 1987b).

Therefore, the purpose of this study was to test the effects of changing the ratio of either $\mathrm{E}$ or $\mathrm{F}$ relative to a standard $1: 1: 1(\mathrm{E}: \mathrm{F}: \mathrm{M})$ bait on the attractive response of both sexes of $D$. brevicomis. Since Tilden and Bedard (1985) had investigated the effects of release rates equivalent to large beetle aggregations, it was decided to decrease the amounts released of either component from about $3.5 \times(183$ females and 872 males $)$ down to $.035 \times$ of their lowest rate or about two females or nine males. In order to obtain these low release rates, a new semiochemical release method, termed "diffusion-dilution," was developed and applied.

\section{METHODS AND MATERIALS}

Diffusion-Dilution Method of Semiochemical Release. Fick's differential equations describing diffusion can serve to determine the instantaneous rate of release of a semiochemical from a capillary tube:

$$
\text { release rate }=-\pi * r^{2} * D *\left(C_{2}-C_{1}\right) / x
$$

Where: $r=$ radius of the tube, $D=$ diffusion coefficient, $C_{2}=$ liquid concentration, $C_{1}=0$ (assuming convection carries vapor away), and $x=$ distance between tube opening and meniscus level of liquid (Villars and Be- 
nedek, 1974) (* = BASIC symbol for multiply). More complicated equations (Brooks, 1980) are needed to describe the release over time as the level of liquid decreases in the tube. In practice, however, it is usually more accurate to measure the release rate over the expected experimental period because one does not know precisely the diffusion coefficient $(D)$ and other contributing factors (e.g., meniscus curvature, surface tension, and temperature effects). Tilden and Bedard (1985) and others (Browne, 1978; Byers and Wood, 1980; Byers, 1982; Tilden et al., 1983) have used 52-mm-long $\times 3.5$-mm-ID glass tubes sealed at the bottom to dispense exo-brevicomin (E) and myrcene (M) by filling the tubes to a level about $40 \mathrm{~mm}$ below the opening. Similarly, they have used $62-\mathrm{mm}-$ long $\times 2.2-\mathrm{mm}-\mathrm{ID}$ tubes to dispense frontalin $(\mathrm{F})$ by filling to a level about 50 $\mathrm{mm}$ below the opening. At these distances, diffusion is rather constant over time (pseudo zero order; Brooks, 1980), and so the measured release rate of each has been considered constant at about $1.5 \mathrm{mg} /$ day (Tilden and Bedard, 1985).

The concentration $\left(C_{2}\right)$ is actually the vapor pressure of the semiochemical, and this can be varied according to Raoult's law, which states that the vapor pressure (release rate) of a volatile substance (semiochemical) is proportional to its mole fraction in a solvent. The following equation can then be derived for purposes of diluting semiochemicals with solvent in order to obtain a specific semiochemical release rate:

$$
m l s=f w s *(\text { gsem/fwsem }- \text { fsem } * \text { gsem } / \text { fwsem }) / \text { fsem } / g s
$$

Where: $m l s=$ milliliters of solvent $f w s=$ formula weight $(=$ molecular weight) of solvent; $g s=$ grams solvent per milliliter (density); gsem = grams of semiochemical; fwsem $=$ formula weight of semiochemical; and fsem $=$ mole fraction of semiochemical $(0<f$ sem $\leq 1)$. For example, a stock solution of $E$ in ethanol that would yield a release rate $10 \%$ that of a neat solution and that is to be made using $0.5 \mathrm{~g}$ of $\mathrm{E}$ would require $0.52 \mathrm{ml}$ of $\mathrm{E}(0.5 \mathrm{~g} * \mathrm{ml} /$ $0.96 \mathrm{~g})$ and $1.6 \mathrm{ml}$ ethanol ([46 $\mathrm{g} /$ mole $*(0.5 \mathrm{~g} / 156 \mathrm{~g} / \mathrm{mole}-0.1 * 0.5 \mathrm{~g} / 156$ $\mathrm{g} / \mathrm{mole}) / 0.1] * \mathrm{ml} / 0.828 \mathrm{~g}$ ). Stock solutions of $\mathrm{E}$ in ethanol that should release about $1 \%, 0.1 \%, 0.01 \%$, and so forth, that of a neat solution can then be made simply from the $10 \%$ solution by serial $1: 10(1+9)$ dilutions.

Testing Pheromone Component Release Rates on Beetles. Field tests of $D$. brevicomis pheromone component ratios were conducted in the Sierra National Forest near Bass Lake, California, at $900 \mathrm{~m}$ elevation, August 20-30, 1985. Various release ratios of $\mathrm{E}$ to $\mathrm{F}+\mathrm{M}$ or $\mathrm{F}$ to $\mathrm{E}+\mathrm{M}$ were composed, based on the formula above, using ethanol as the diluting solvent and the appropriate glass tubes (each component alone) of Tilden and Bedard (1985) described above (Table 1, Figure 1A). Tubes with fresh solution were replaced each morning in order to minimize release rate errors due to differential loss of the ethanol and the consequent effect on concentration of the semiochemical. Two groups (about $100 \mathrm{~m}$ apart) of eight sticky traps each (6-mm mesh metal-screen cylinder, 19 
Table 1. Catches of Male and Female Dendroctonus brevicomis (and SeX Ratios) and Temnochila chlorodia on STICKY TRAPS RElEASING VARIOUS RATIOS OF Ethanol (A), Frontalin (F), exo-Brevicomin (E), and Mrrcene (M)

\begin{tabular}{|c|c|c|c|c|c|}
\hline \multirow[b]{2}{*}{ Component release rates $^{a}$} & \multicolumn{3}{|c|}{ D. brevicomis } & \multicolumn{2}{|c|}{ T. chlorodia } \\
\hline & Male & Female & $\mathrm{M} / \mathrm{F}$ sex ratio $(95 \% \mathrm{BCL})^{b}$ & Male & Female \\
\hline $\mathrm{A}^{c}$ & 0 & 0 & & 0 & 0 \\
\hline $\mathrm{F}+\mathrm{M}+\mathrm{A}^{c}$ & 6 & 10 & $0.60(0.23-1.59)$ & 0 & 0 \\
\hline $\mathrm{E}+\mathrm{M}+\mathrm{A}^{c}$ & 8 & 3 & $2.67(0.77-9.26)$ & 4 & 2 \\
\hline $0.01 \mathrm{~F}\left(\right.$ in $\left.\mathrm{A}^{d}\right)+\mathrm{E}+\mathrm{M}$ & $53 * * e$ & $57 *$ & $0.93(0.64-1.35)$ & 5 & 4 \\
\hline $0.01 \mathrm{E}\left(\right.$ in $\left.\mathrm{A}^{c}\right)+\mathrm{F}+\mathrm{M}$ & $60 * *$ & $68 * *$ & $0.88(0.62-1.25)$ & 0 & 0 \\
\hline $0.1 \mathrm{~F}\left(\right.$ in $\left.\mathrm{A}^{d}\right)+\mathrm{E}+\mathrm{M}$ & 98 & $107^{* * *}$ & $0.92(0.70-1.20)$ & 4 & 7 \\
\hline $0.1 \mathrm{E}\left(\right.$ in $\left.\mathrm{A}^{c}\right)+\mathrm{F}+\mathrm{M}$ & $124 * *$ & $158^{* * *}$ & $0.78(0.62-0.99)$ & 2 & 1 \\
\hline $\mathrm{E}+\mathrm{F}+\mathrm{M}+\mathrm{A}^{c}$ & 155 & 170 & $0.91(0.73-1.13)$ & 5 & 4 \\
\hline
\end{tabular}

${ }^{a} \mathrm{E}, \mathrm{F}$ and $\mathrm{M}$ were each released at approximately $1.5 \mathrm{mg} /$ day or fraction thereof.

${ }^{b}$ Sex ratios were not significantly different $\left(\mathrm{P}>0.05, \chi^{2}\right) 95 \% \mathrm{BCL}=95 \%$ binomial confidence limits.

${ }^{c} \mathrm{~A}$ (ethanol) was released from E-tubes at about $66 \mathrm{mg} /$ day.

${ }^{d} \mathrm{~A}$ (ethanol) was released from F-tubes at $21 \mathrm{mg} /$ day.

${ }^{e}$ Wilcoxon matched-pair tests indicated catch was significantly different from the catch on the corresponding $10 \%$ serial rate (or control for the 0.01 rate) within the same sex at $P<0.05\left(^{*}\right.$ ) or $P<0.01$ (**) $^{*}$.

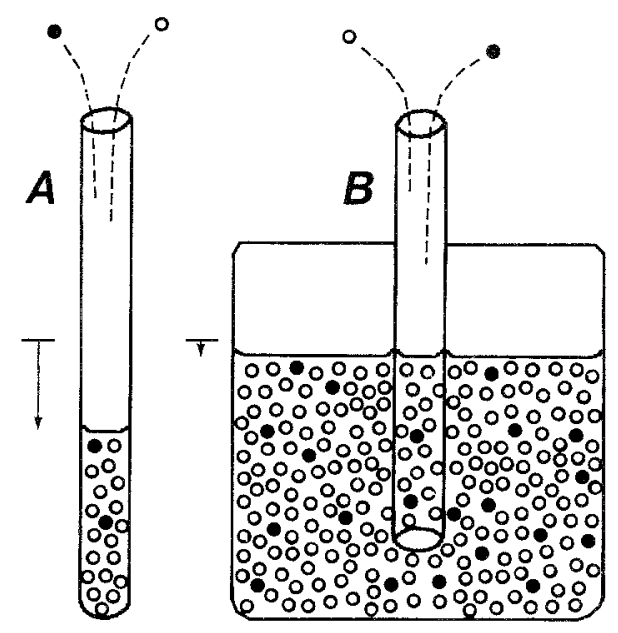

FIG. 1. Cross-sections of two possible dispensers for semiochemical release that demonstrate Raoult's law of solute-solvent volatization. The mole percentages of semiochemical (๑) and solvent $(\bigcirc)$, e.g., $10 \%$ and $90 \%$ as shown, determine the corresponding release rates of each compared to respective neat solutions as controlled by the diffusion rate through the tube. Dispenser B is preferable to dispenser A because the larger reservoir remains practically constant, both in concentration and level, as does the release rate, during prolonged periods of release. 
$\mathrm{cm}$ diam. $\times 30.5 \mathrm{~cm}$ high, coated with Stikem Special placed at $1.2 \mathrm{~m}$ height; Bedard and Browne, 1969) contained the respective baits (Table 1) in sun/wind protective dispensers (Byers and Wood, 1980). The traps were randomized each day (six, 1-day replicates/trap) within a group and were spaced $25 \mathrm{~m}$ apart on a line. D. brevicomis and Temnochila chlorodia (Mannerheim) were collected each day and their sex was determined.

Wilcoxon matched-pair tests were used to compare the male and female catches on the $1: 1: 1(\mathrm{E}: \mathrm{F}: \mathrm{M})$ ratio to their corresponding catches on the 0.1 $\mathrm{E}$ or $0.1 \mathrm{~F}$ ratios, and these ratios were compared to corresponding 0.01 dilutions, while the 0.01 dilutions were compared to each of the components alone. Binomial confidence limits for sex ratios were calculated (Byers and Wood, 1980) and compared for significant differences with chi square. The relationships of $E$ or $F$ release $(\mathrm{mg} /$ day) with trap catch $(E: F: M=100 \%)$ were determined using several regression equations [power, exponential, logarithmic, linear, $Y=a+b X^{2}$, and $\left.Y=\mathrm{a}+\mathrm{b} / \mathrm{X}\right]$.

\section{RESULTS}

The alcohol-diluted $\mathrm{E}$ and $\mathrm{F}$ tube dispensers seemed to yield the predicted release rates based on the logarithmic relationship with the catch of $D$. brevi-

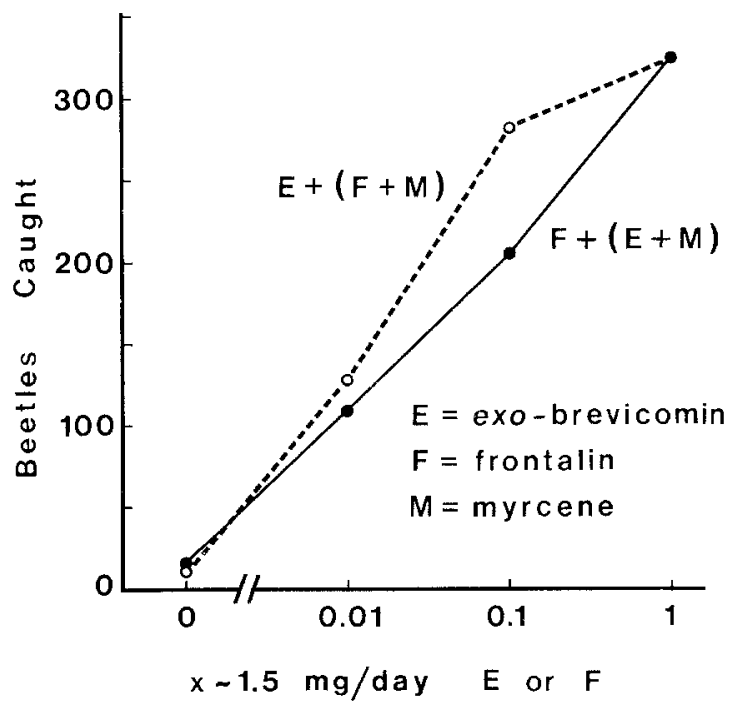

FIG. 2. Attraction of D. brevicomis to pheromone component ratios released from sticky traps. Various rates of $\mathrm{E}$ (exo-brevicomin) plus constant rates of $\mathrm{F}$ (frontalin) and $\mathrm{M}$ (myrcene), each at $1.5 \mathrm{mg} /$ day, or various rates of $\mathrm{F}$ plus constant rates of $\mathrm{E}$ and $\mathrm{M}$ (each point represents mean of 12 one-day replicates) were released in the Sierra National Forest, August 20-30, 1985. 
comis (Figure 2). The increases in catch of each sex to increases in either component were in most cases statistically significant for each 10 -fold increase in release (Table 1). However, the catch on the $1: 1: 1$ ratio at $1.5 \mathrm{mg}$ each/day was not significantly different from that on the $0.1 \mathrm{E}$ or $0.1 \mathrm{~F}$ releases. The sex ratios of catch on all pheromone component ratios and rates were comparable and not significantly different based on chi-square analysis (Table 1). However, on the $\mathrm{E}$ or $\mathrm{F}$ components alone there is an indication of sexual preferences, but the numbers are too low for reliable statistics. It is interesting to note that the total catches for each of the component ratios at a particular release rate were similar, as were the catches of each sex (Figure 2, Table 1). Ethanol (A in Table 1) was perhaps not the most appropriate choice for solvent as some "less aggressive" bark beetles use it to locate hosts (Moeck, 1970; Klimetzek et al., 1986). However, ethanol did not appear to be attractive to D. brevicomis when presented alone, although the possibility remains that it might have enhanced the attraction to the pheromone components.

Logarithmic relationships (linear increase in attraction with 10 -fold increases in pheromone release) are usually expected for dosage-response curves. Several curvilinear regressions of $D$. brevicomis component release $(X)$, but not including $X=0$ since this value is infinitely smaller than 0.01 , against percent catch $(Y), \mathrm{E}: \mathrm{F}: \mathrm{M}$ catch $=100 \%$, confirmed that logarithmic curves had the highest coefficients of determination. The logarithmic relationship of male response to $\mathrm{F}(+\mathrm{E}+\mathrm{M})$ from 0.01 to 1 had an $r^{2}=0.99, Y(\%)=92.9+$ $14.3 \ln \mathrm{X}$, and female response to $\mathrm{F}(+\mathrm{E}+\mathrm{M})$ over the same range had an $r^{2}$ $=0.99, Y(\%)=92.9+14.4 \operatorname{lnX}$. The male response to $\mathrm{E}(+\mathrm{F}+\mathrm{M})$ from 0.01 to 1 had a $\mathrm{r}^{2}=0.96, Y(\%)=98.2+13.3 \ln \mathrm{X}$, and female response an $r^{2}=0.84, Y(\%)=102.4+13.0 \ln \mathrm{X}$.

T. chlorodia was caught in a pattern consistent with an attraction to E only, as noted previously (Bedard et al., 1980). However, both sexes seem equally responsive to release rates of $\mathrm{E}$, and they seem less sensitive than $D$. brevicomis because proportionately less were caught on the traps with the 0.1 and $0.01 \mathrm{E}$ releases (Table 1).

\section{DISCUSSION}

Diffusion-Dilution Release of Semiochemicals. Let us first consider diffusion from the glass tube with a neat solution of semiochemical in which the release rate is inversely proportional to the depth of the meniscus level in the tube (equation 1). If we assume an average release rate of $F$ of $1.5 \mathrm{mg} /$ day over 10 days, according to Tilden and Bedard (1985), when the meniscus changed from 53 below the top (as it was similar to this, see Methods and Materials) to a level $4 \mathrm{~mm}$ lower after 10 days (about $14.5 \mathrm{mg}$ loss), then the beginning instantaneous rate on the first day should have been $1.56 \mathrm{mg} /$ day and the ending rate $1.45 \mathrm{mg} /$ day (equation 1 ). Another viewpoint is that the change in meniscus 
level is inversely proportional to the square root of time (Brooks, 1980; Kydonieus, 1980). Thus, if we begin with a release of $12.4 \mathrm{mg} /$ day at $t=1$, solved by successive approximation by computer, with a nearly full tube of $F$, then after 63 days of elution we would expect a rate of $1.56 \mathrm{mg} /$ day and, 10 days later, about $1.45 \mathrm{mg} /$ day (as above). The assumed total release [ $\Sigma_{t=1}^{732} 12.4 /$ $\left.(t / 10)^{-1 / 2}\right]$ would equal $206.5 \mathrm{mg}$, which corresponds to a meniscus level change in the $\mathrm{F}$ tube of $57.1 \mathrm{~mm}$, close to our $57-\mathrm{mm}$ ending level assumed above.

These calculations indicate that for all practical purposes the release rate is constant (pseudo zero order) for a particular test period. This is true as long as the meniscus is relatively far from the tube opening and the level does not change much, such as when low amounts are released from a not-too-volatile substance (pheromone). The advantage of tube dispensers is that the release rate can be immediately adjusted to the pseudo constant rate by placing a small amount at a level several centimeters from the opening. The weight and volume changes can also be easily determined by weighing and by measuring meniscus level changes.

Larger release rate discrepencies should be expected when using the above diffusion method with diluted semiochemical (diffusion-dilution), although they should be much less than an order of magnitude used here. The solvent used was ethanol, which is not too volatile for a solvent $\left(\mathrm{bp} 78.5^{\circ} \mathrm{C}\right.$, vapor pressure $61-122 \mathrm{~mm}$ at $\left.26-36^{\circ} \mathrm{C}\right)$ but much more so than $\mathrm{M}\left(2.06-3.42 \mathrm{~mm}\right.$ at $26-36^{\circ} \mathrm{C}$, which, based on the neat release rate, is similar to E). However, the higher volatility of ethanol meant that proportionately more was released than $\mathrm{E}$ or $\mathrm{F}$ over time, which would cause the mole percentage of these compounds to increase during the day. Thus, at most we would expect an increase of $\mathrm{E}$ or $\mathrm{F}$ release of $43 \%$ during the 10 -h flight period ( 0900 to $1900 \mathrm{hr}$ ) based on the measured loss of ethanol in the tube ( $30 \%$ of total). Since some E or F also was released, the actual increase was less than $43 \%$.

A compensatory phenomenon was simultaneously occurring since the meniscus level also fell about $30 \%$; this would cause the reverse effect and diminish the rate of release (at most $9 \%$ ). These partially compensating effects occurred throughout the day, so the error in release rate became larger with time. However, variation in temperature probably had effects at least as, or more, severe (up to $100 \%$ as seen from the vapor pressures over the daily temperature range, above). Absolute errors on the order of $10 \%$ could be possible if calibration had been at sea level but testing was at higher altitudes (L.E. Browne, personal communication). In any case, these errors during the course of the day were on the order of less than $50-100 \%$, insignificant compared to the $1000 \%$ differences between each serial $1: 10$ dilution.

The tube-type release device is adequate for most experiments, but if tests for longer periods and constant rates are desired, a similar device with a larger reservoir is preferred (Figure 1B). Both dispensers shown in Figure 1 would 
have the same release rate initially since their openings and diffusion distances are identical. However, as noted above, after a time both the concentration of semiochemical and diffusion distance change in the tube, while a similar release from the larger reservoir has little effect (Figure 1). Many other solvents could be used. Theoretically, it is desirable to have a solvent that has chemical properties and polarity similar to the released semiochemical. Work is now underway to determine the release rates of various semiochemicals in different solvents by means of porapak $Q$ volatile collections and quantitative gas-liquid chromatography.

Comparison with Other Controlled Release Methods. The first dispensers that released synthetic bark beetle pheromones used filter paper (Wood et al., 1967) or metal tubes containing gas-liquid chromatographic packing to hold the compounds until they evaporated (Wood et al., 1968). Since then, experimental elution devices have included four major types. The first type uses various absorbent materials, such as rubber septa, and is widely used with moth pheromones. Depending on the absorbent, this type generally has release curves that decrease exponentially or geometrically, thus being rather constant after several days of elution. I believe this method is less desirable because the rates change dramatically soon after application, and it is difficult to specify and vary the release without much laborious measurement. A second method has used wicks dipped in semiochemical (Tilden et al., 1979; Bedard et al., 1980), but the inexact surface area and physical properties of wicks make it difficult to either specify or vary the release accurately. A third method uses semipermeable plastic bags or vials to enclose semiochemical (Vité et al., 1986; Klimetzek et al., 1986; Schlyter et al., 1987b). This results in a constant release rate that is proportional to the thickness of the plastic and its surface area (Kydonieus, 1980). However, it is easy to see that release rates over several orders of magnitude are impractical due to the limitation of dispenser sizes. Furthermore, much testing is needed for each particular vial or bag to determine the release rate, so rates cannot be specified over a broad range. In all these methods, the absorbent, wick, or semipermeable plastic could have degrading effects on a particular semiochemical which would not be expected if inert materials are used.

The "test-tube" type dispenser used here has many advantages over the other three methods in that glass will not affect the semiochemical, and the rate can be specified depending on the area of the opening and the level of the liquid. The criticism of Kydonieus (1980) that capillary reservoir systems have parabolic curves of release (large amounts initially) can be easily overcome by using tubes with liquid levels that are several centimeters from the top opening. The major problem has been that a large array of tube sizes is needed (which cannot be varied freely) to encompass several orders of magnitude in release, the same problem as with the plastic bags. However, by mole percentage dilution, one 
can specify any desired rate that is less than a known rate of a neat semiochemical. A mixture of semiochemicals probably could be released from one dispenser solution if their mole percentages were relatively small ( $<10 \%$ of neat). These small mole percentages would tend to minimize any unpredicted effects on both vapor pressures and possible physical interactions between semiochemical molecules.

Attraction to Pheromone Component Ratios. Both male and female $D$. brevicomis had similar attraction levels over the concentration range of either $\mathrm{E}$ or $\mathrm{F}$ (with constant release rates of $\mathrm{M}$ and the opposite component). In fact, one may find it somewhat surprising that all the logarithmic relationships were very similar (see Results, Figure 2) because males seem to prefer E alone while females prefer F alone (Bedard et al., 1969; Vité and Pitman, 1969; Pitman and Vité, 1971; Hughes and Pitman, 1970; Byers, 1987) (Table 1). On the other hand, Byers and Wood (1981) found that both sexes were equally responsive (logarithmic relationship) at each step in a concentration range of $\mathrm{E}: \mathrm{F}: \mathrm{M}$ covering five orders of magnitude in the laboratory. Similarly, regression analysis of the results of Tilden and Bedard (1985) shows that D. brevicomis males and females have logarithmic attraction levels to increasing $\mathrm{E}: \mathrm{F}: \mathrm{M}$ release rates $\left(r^{2}\right.$ $=0.82-0.99$ ) at a center trap and traps $5 \mathrm{~m}$ away. Furthermore, the separation of $\mathrm{E}$ and $\mathrm{F}$ components either horizontally or vertically from 0 to $3 \mathrm{~m}$ (perpendicular to the mean wind) decreased the catch on each component but more or less equally for both sexes (Byers, 1987). Thus, except for the components alone, the sexes seem to respond equally to all comparable ratios and concentrations of E:F. This suggests that each component is equally important and has a similar function in the synergism and in the orientation to sources.

In contrast, Schlyter et al. (1987b) varied the ratios and rates of release of (-)-cis-verbenol (cV) and 2-methyl-3-buten-2-ol (MB), keeping one or the other constant, and found differences in the response of I. typographus to each component. They suggested that MB was more important for close-range orientation, while $\mathrm{cV}$ was more important further downwind from the source. Their theory was based largely on differences between catches on traps placed at the source and those placed a few meters away. However, regression analysis of their results indicates both $\mathrm{MB}$ and $\mathrm{cV}$ have logarithmic relationships $\left(r^{2}=\right.$ $0.88-0.98$ ) of concentration ratio and catch on both "close and long-range traps." Further work on component release ratios with traps at varying distances from the source is needed for both bark beetle species before we can form definitive theories on the function of the synergistic components during the upwind orientation to pheromone.

The release of various extreme component ratios is rather unnatural. A $1: 100$ ratio of $F: E(0.01 \mathrm{~F})$ at $1.5 \mathrm{mg} \mathrm{E} /$ day would simulate nine males with 183 females, which probably never occurs in nature. Despite these extreme sex ratios of simulated feeding beetles, the responses of $D$. brevicomis to the above 
ratio $(0.01 \mathrm{~F})$ or to 872 males with two females $(0.01 \mathrm{E})$ were still significant, catching about $34 \%$ and $39 \%$, respectively, as many beetles as that on $\mathrm{E}: \mathrm{F}$ (872 males and 183 females).

In contrast, some moths can be exceptionally sensitive to component ratio variations of as little as $10 \%$ or less when the synergists are $E$ and $Z$ isomers of long-chain monounsaturated acetates (Roelofs and Cardé, 1977; Cardé and Baker, 1984). As shown here and by Schlyter et al., (1987b), one reason bark beetles may be less sensitive to component ratios than moths could be because they must respond to ratios from various groups of beetles and not to a "preferred"' individual with a consistent ratio. Initially the beetle aggregation would be composed of small numbers so the variation in semiochemical ratios would be expected to be rather large until later when a statistical mass-average would result. However, male moths would be better adapted if they were able to respond to the individual variation in ratios of many potential female mates-this variation is theoretically larger than the variation between small populations, all other things being equal. Another possible reason is that bark beetles often synthesize pheromone components from monoterpene precursors in the tree, where we expect a large variation (Sturgeon 1979), whereas moths synthesize their components de novo (Bjostad and Roelofs, 1981). This could explain the insensitivity of $I$. typographus for $\mathrm{cV}: \mathrm{MB}$ ratios since $\mathrm{cV}$ is made from $\alpha$ pinene in Norway spruce (Klimetzek and Francke, 1980). In D. brevicomis, biosynthesis of $\mathrm{F}$ does not seem to be affected by the host, while $\mathrm{E}$ is only produced by the female during feeding (Byers, 1983a), although we do not know if a host precursor is involved. Finally, both I. typographus and D. brevicomis are faced with a changing ratio between pheromone components during the colonization of a tree, introducing even more potential variation (Birgersson et al., 1984; Byers et al., 1984).

Pheromone Qualification. The term "pheromone" was defined by Nordlund (1981) in his semiochemical glossary as "a substance that is secreted by an organism to the outside that causes a specific reaction in a receiving organism of the same species." Using this definition without the implicit quantitative qualification, it is possible to believe erroneously that one has identified a "pheromone" when in fact the substance is irrelevant. This is because many secreted substances, if presented in unnaturally high concentrations, could cause a specific reaction (death or repellency and possibly inhibition, interruption, or disruption of other behaviors). Furthermore, many substances are believed to be active only in small amounts relative to other pheromones, e.g., verbenone in D. frontalis (Rudinsky 1973), 2,3-MCH in D. pseudotsugae (Rudinsky and Ryker, 1980), or ipsdienol in I. typographus (Schlyter et al., 1987c). Some bark beetle pheromones are attractive at lower release rates but become progressively less attractive to the male sex only, e.g., I. paraconfusus (Byers, 1983b) and I. typographus (Schlyter et al., 1987b,c). Many moth species are 
known to be disrupted by higher, and unnatural, concentrations of their pheromone (cf. Cardé, 1984). Therefore, in order to properly define an isolated substance as a certain type of semiochemical, one should have a knowledge of the natural secretion rate compared to the effects of release of synthetic substances on the receiving organism in relation to its ecology. It is hoped that the diffusion-dilution method presented here will aid chemical ecologists in answering the second question concerning release rates of synthetic compounds.

Acknowledgments-This work was supported in part by grants from USA, NSF (INT8503520), and Sweden, STU (84-3937), NFR, FRN, and SJFR. I am appreciative of the USFS and W.D. Bedard, P.E. Tilden, and M.I. Haverty for providing the facilities for research in the field. I am very grateful to P.E. Tilden for helpful assistance and information concerning my field studies. I would like to thank D.L. Wood, Department of Entomological Sciences, University of California, Berkeley, for providing me with a research base in collaboration with J. Löfqvist and the Department of Animal Ecology, University of Lund, Sweden. I also appreciate the helpful discussions with my colleagues, $\mathrm{O}$. Anderbrant and F. Schlyter, here in Lund.

\section{REFERENCES}

BEDARD, W.D., and BROWNE, L.E. 1969. A delivery-trapping system for evaluating insect chemical attractants in nature. J. Econ. Entomol. 62:1202-1203.

Bedard, W.D., Tilden, P.E., Wood, D.L., Silverstein, R.M., Brownlee, R.G., and Rodin, J.O. 1969. Western pine beetle: Field response to its sex pheromone and a synergistic host terpene, myrcene. Science 164:1284-1285.

Bedard, W.D., Wood, D.L., Tilden, P.E., Lindahl, K.Q., Jr., Silverstein, R.M., and Rodin, J.O. 1980. Field response of the Western pine beetle and one of its predators to host- and beetle-produced compounds. J. Chem. Ecol. 6:625-641.

Birgersson, G., SCHLYTER, F., LöFQvist, J., and Bergström, G. 1984. Quantitative variation of pheromone components in the spruce bark beetle Ips typographus from different attack phases.

J. Chem. Ecol. 10:1029-1055.

BJostAD, L.B., and RoEloFs, W.L. 1981. Sex pheromone biosynthesis from radiolabeled fatty acids in the redbanded leafroller moth. J. Biol. Chem. 256:7936-7940.

BRooks, T.W. 1980. Controlled vapor release from hollow fibers: Theory and applications with insect pheromones, pp. 165-193, in A.F. Kydonieus (ed.). Controlled Release Technologies: Methods, Theory, and Applications, Vol II. CRC Press, Boca Raton, Florida.

BRowne, L.E. 1978. A trapping system for the Western pine beetle using attractive pheromones. J. Chem. Ecol. 4:261-275.

Browne, L.E., Wood, D.L., Bedard, W.D., Silverstein, R.M., and West, J.R. 1979. Quantitative estimates of the Western pine beetle attractive pheromone components, exo-brevicomin, frontalin, and myrcene in nature. J. Chem. Ecol. 5:397-414.

BYERS, J.A. 1982. Male-specific conversion of the host plant compound, myrcene, to the pheromone, (+)-ipsdienol, in the bark beetle, Dendroctonus brevicomis. J. Chem. Ecol. 8:363371.

BYERS, J.A. 1983a. Influence of sex, maturity and host substances on pheromones in the guts of the bark beetles, Ips paraconfusus and Dendroctonus brevicomis. J. Insect Physiol. 29:5-13.

BYERS, J.A. 1983b. Sex-specific responses to aggregation pheromone: Regulation of colonization density by the bark beetle Ips paraconfusus. J. Chem. Ecol. 9:129-142. 
BYERS, J.A. 1987. Interactions of pheromone component odor plumes of Western pine beetle. $J$. Chem. Ecol. 13:2143-2157.

BYERS, J.A., and WOOD, D.L. 1980. Interspecific inhibition of the response of the bark beetles, Dendroctonus brevicomis and Ips paraconfusus. J. Chem. Ecol. 6:149-164.

BYERS, J.A., and WOOD, D.L. 1981. Interspecific effects of pheromones on the attraction of the bark beetles, Dendroctonus brevicomis and Ips paraconfusus in the laboratory. J. Chem. Ecol. 7:9-18.

Byers, J.A., WoOd, D.L., Craig, J., and Hendry, L.B. 1984. Attractive and inhibitory pheromones produced in the bark beetle, Dendroctonus brevicomis, during host colonization: Regulation of inter- and intraspecific competition. J. Chem. Ecol. 10:861-877.

CARDÉ, R.T. 1984. Chemo-orientation in flying insects, pp. 111-124, in W.J. Bell and R.T. Cardé (eds.). Chemical Ecology of Insects. Chapman and Hall, London.

CARDÉ, R.T., and BAKER, T.C. 1984. Sexual communication with pheromones, pp. 355-383, in W.J. Bell and R.T. Cardé (eds.). Chemical Ecology of Insects. Chapman and Hall, London.

Hughes, P.R., and PITMAN, G.B. 1970. A method of observing and recording the flight behavior of tethered bark beetles in response to chemical messengers. Contrib. Boyce Thompson Inst. $24: 329-336$.

KLIMETZEK, D., and FranCKE, W. 1980. Relationship between the enantiomeric composition of $\alpha$-pinene in host trees and the production of verbenols in Ips species. Experienta 36:13431345.

Klimetzek, D., Köhler, J., Vité, J.P., and Kohnle, U. 1986. Dosage response to ethanol mediates host selection by "secondary" bark beetles. Naturwissenschaften 73:270-272.

KYDONIEUS, A.F. 1980. Fundamental concepts of controlled release, pp. 1-19, in A.F. Kydonieus (ed.). Controlled Release Technologies: Methods, Theory, and Applications. Vol I. CRC Press, Boca Raton, Florida.

MOECK, H.A. 1970. Ethanol as the primary attractant for the ambrosia beetle Trypodendron lineatum (Coleoptera: Scolytidae). Can. Entomol. 102:985-995.

NordLund, D.A. 1981. A glossary of terms used to describe chemicals that mediate intra- and interspecfic interactions, pp. 495-497, in E.R. Mitchell (ed.). Management of Insect Pests with Semiochemicals. Plenum Press, New York.

PitMAn, G.B., and VitÉ, J.P. 1971. Predator-prey response to Western pine beetle attractants. $J$. Econ. Entomol. 64:402-404.

RoElofs, W.L. 1979. Establishing Efficacy of Sex Attractants and Disruptants for Insect Control. Entomological Society of America, College Park, Maryland. 97 pp.

Roelofs, W.L., and CARDÉ, R.T. 1977. Responses of Lepidoptera to synthetic sex pheromone chemicals and their analogues. Annu. Rev. Entomol. 22:377-405.

Rudinsky, J.A. 1973. Multiple functions of the southern pine beetle pheromone verbenone. Environ. Entomol. 2:511-514.

RUDINSKY, J.A., and RYKeR, L.C. 1980. Multifunctionality of Douglas-fir pheromone 3,2-MCH confirmed with solvent dibutyl phthalate. J. Chem. Ecol. 6:193-201.

Schlyter, F., Birgersson, G., Byers, J.A., Löfqvist, J., and Bergström, G. 1987a. Field response of the spruce bark beetle, Ips typographus, to aggregation pheromone candidates. $J$. Chem. Ecol. 13:701-716.

SCHLYTER, F., LÖFQVIST, J., and BYERS, J.A. 1987b. Behavioural sequence in the attraction of the bark beetle Ips typographus to pheromone sources. Physiol. Entomol. 12:185-196.

SCHLYTER, F., BYERS, J.A., and LöFQVIST, J. 1987c. Attraction to pheromone sources of different quantity, quality and spacing: Density-regulation mechanisms in the bark beetle Ips typographus. J. Chem. Ecol. 13:1503-1523.

Stewart, T.E., Plummer, E.L., McCandless, L.L., West, J.R., and Silverstein, R.M. 1977. 
Determination of enantiomer composition of several bicyclic ketal insect pheromone components. J. Chem. Ecol. 3:27-43.

STURGEON, K.B. 1979. Monoterpene variation in ponderosa pine xylem resin related to Western pine beetle predation. Evolution 33:803-814.

TILDEN, P.E., and BEDARD, W.D. 1985. Field response of Dendroctonus brevicomis to exo-brevicomin, frontalin, and myrcene released at two proportions and three levels. J. Chem. Ecol. 11:757-766.

Tilden, P.E., Bedard, W.D., Wood, D.L., Lindahl, K.Q., and Rauch, P.A. 1979. Trapping the Western pine beetle at and near a source of synthetic attractive pheromone: Effects of trap size and position. J. Chem. Ecol. 5:519-531.

Tilden, P.E., Bedard, W.D., Lindahl, K.Q., Jr., and WoOD, D.L. 1983. Trapping Dendroctonus brevicomis: Changes in attractant release rate, dispersion of attractant, and silhouette. J. Chem. Ecol. 9:311-321.

VILlARS, F.M.H., and BENEDEK, G.B. 1974. Physics with Illustrative Examples from Medicine and Biology, Vol 2. Addison-Wesley, Reading, Massachusetts. pp. 66-92.

VITÉ, J.P., and PITMAN, G.B. 1969. Aggregation behavior of Dendroctonus brevicomis in response to synthetic pheromones. J. Insect Physiol. 15:1617-1622.

Vité, J.P., Volz, H.A., Parva, M.R., and BaKKe, A. 1986. Semiochemicals in host selection and colonization of pine trees by the pine shoot beetle Tomicus piniperda. Naturwissenschaften 73:39-40.

WOOD, D.L., STARK, R.W., SILVERSTEIn, R.M., and Rodin, J.O. 1967. Unique synergistic effects produced by the principle sex attractant compounds of Ips confusus (LeConte) (Coleoptera: Scolytidae). Nature 215:206.

Wood, D.L., Browne, L.E., Bedard, W.D., Tilden, P.E., Silverstein, R.M., and Rodin, J.O. 1968. Response of Ips confusus to synthetic sex pheromones in nature. Science 159:13731374.

Wood, D.L., Browne, L.E., Ewing, B., Lindahl, K., Bedard, W.D., Tilden, P.E., Mori, K., Pitman, G.B., and Hughes, P.R. 1976. Western pine beetle: Specificity among enantiomers of male and female components of an attractant pheromone. Science 192:896-898. 